\title{
NOTAS SOBRE EL PRECIO DE LA TIERRA \\ EN ESPAÑA (1836-1914)
}

\author{
RICARDO ROBLEDO HERNANDEZ \\ Universidad Autónoma de Barcelona
}

\section{Introducción}

Al abordar el tema del precio de la tierra hay dos tipos de preocupaciones - de índole teórica y metodológica- que merecen ser afrontadas de entrada. Respecto a las primeras, un criterio excesivamente rígido de lo que se entiende por mercancía nos situaría frente a la paradoja de un bien que genera un precio, pero que carece de valor al no ser un producto específico del trabajo humano. Sin embargo, si aceptamos llamar mercancia a aquello que es comprado y vendido ( $y$, por tanto, circula) en unas relaciones capitalistas de producción y distribución, no deberíamos tener reparos al hablar de precio de la tierra: igual que se compra la fuerza de trabajo, también se adquiere en el mercado este medio de producción que es la tierra ${ }^{1}$.

Ahora bien, alejar los reparos respecto a este bien económico que es la tierra diciendo que posee un mercado como cualquier otro bien no elimina los obstáculos que supone conocer el precio de un bien tan complejo, pues, aparte de carecer de homogeneidad, sirve a la vez de instrumento de trabajo y de valor refugio que atrae capitales en circunstancias variadas ${ }^{2}$.

Las dificultades señaladas se acrecientan si de los recelos teóricos o de metodología se desciende a los problemas cotidianos del historiador, que se arriesga a elaborar precios de cien años atrás cuando las fuentes son escasas o endebles, o se topa con medidas de superficie que bajo una misma denominación de fanega u obrada encierran distintas cantidades ${ }^{3}$. La acumulación de obstáculos tienta al desánimo, aunque no deja de ser sorprendente que, en una etapa en que la tierra era fuente principal de empleo y producción en España, sigamos sin disponer de unos índices, al menos, alrededor de los

' K. TRIBE, "Propietat econòmica i teorització de la renda de la terra", Estudis d'Història Agrària, núm. 2 (1979), p. 19.

2 G. Desert, "La valeur venale de la terre...", en M. LÉvy LEBoyer, La revenu agricole et la rente foncière en Basse Normandie, París, 1972, p. 97.

${ }^{3}$ Estas cuestiones aparecen detalladas en el apéndice, al final de este estudio. 
cuales oscilaron un buen número de transacciones hasta entonces congeladas. Por tal razón, me he decidido a presentar este trabajo pensando que, pese a todo, es mejor contar con precios medios y estimaciones (cuanto más sólidas mejor) que renunciar en aras de una precisión, más bien difícil de lograr por ahora.

Nos sumamos, en definitiva, a la intención de uno de los pioneros de esta clase de estudios en España: «tratándose del valor de la tierra, que es la máquina fundamental del labrador, todo cuanto se haga por conocerla será un trabajo fructuoso» ${ }^{4}$.

\section{A. Evolución global del precio de la tierra}

Nuestro estudio se divide en dos partes. En la primera analizaré, de forma general, las variaciones en el precio de la hectárea de secano, fundamentalmente de cereales. Lo relativo a las fuentes y sus resultados figura en el apéndice final. Una vez que dispongamos de unos precios de la tierra con cierta solvencia (en torno a tres cortes, aproximadamente $1837-45,1875-78,1902$ 1908), nos plantearemos algo más interesante: cómo integrar dicha evolución en el contexto de la economía española y dentro del panorama europeo.

\section{A.1. De las desamortizaciones a la crisis de fines del XIX: la inauguración definitiva de un mercado de tierras}

A partir de 1836 se produce en España, de forma ya irreversible, la inauguración del mercado territorial. Antes de esta fecha no habían estado ausentes las enajenaciones de fincas rústicas o urbanas, destacando, en las etapas más próximas, la desamortización de Godoy o la que tuvo efecto en el Trienio. Además, y en fechas similares, está la venta de fincas de mayorazgos, aunque sobre esto apenas tengamos más noticias que las de un relajamiento de las normas que impedían la libre disposición de los bienes vincula$\operatorname{dos}^{5}$ o el de sus repercusiones en Barcelona cuando, en octubre de 1820 , se

4 J. Hidalgo Tablada, Curso de economía rutal española, Madrid, 1864, tomo I, página 176.

${ }^{3}$ La crisis del Antiguo Régimen que se abre en España a fines del siglo xvirI obliga a tomar diversas medidas con que hacer frente a los premiosos apuros de la Hacienda. A partir de 1789 se conceden diversas facultades, entre las que destaca la de 1798 que permite al poseedor de mayorazgos enajenar bienes vinculados, "sin embargo de cualesquiera cláusulas prohibitivas", con tal de que impusiera el valor liquido en la Caja de Amortización con el interés del 3 por 100. Cfr. R. HerR, "Hacia el derrumbe del Antiguo Régimen: crisis fiscal y desamortización bajo Carlos IV", Moneda y Crédito, núm. 118 (1971), p. 48; véase tambièn B. Clavero, Mayorazgo. Propiedad feudal..., Madrid, Siglo XXI, 1974, p. 333. 
aprueba la Ley de Desvinculación ${ }^{6}$. Ciertamente, como apunta Angels Solà, estamos ante un desequilibrio de conocimientos de las diversas medidas liberales que forzaron «una nueva estructura agraria, base para la penetración del capitalismo en el campo", siendo la menos favorecida la desvinculación, y esto se incrementa mucho más cuando nos referimos a la etapa anterior a 1836. Sin embargo, debió existir cierta movilidad de la propiedad nobiliaria (tan difícil de calcular, por lo demás, como la ocurrida posteriormente, donde sólo se dispone de unas cifras aisladas de S. Millet, sometidas a duras críticas). Como es sabido, la enajenación de bienes de mayorazgo requería un permiso real, que la Corona concedía con cierta regularidad; una investigación sobre protocolos notariales demuestra que alguna de las grandes casas acudieron de forma destacada a la venta de bienes vinculados ${ }^{7}$. Es más significativo, de cara a la ampliación del mercado, darse cuenta de la existencia de bienes libres no sujetos a la rigidez de las cláusulas sucesorias del mayorazgo, y que la nobleza fue ampliando progresivamente en una estrategia de reserva económica, tanto en seguridad de ataques contra mayorazgos como de disponer de fortuna para los hijos naturales excluidos de los mismos ${ }^{8}$.

Con todo, pese a que la Corona, por sus apuros hacendísticos, hubiera lanzado al mercado baldíos y comunales desde el siglo xvi, y los nobles se hubiesen desprendido de bienes libres o vinculados según su grado de endeudamiento, difícilmente puede hablarse de un mercado de tierras en cuanto tal, por la protección privilegiada que tenía la propiedad del Antiguo Régimen o, como diría algún jurista, por su «imperfección». De hecho, lo menos que puede decirse es que antes de $1836-37$ se producían situaciones contradictorias, como las de liberalizar arrendamientos, en un país que no tenía tierra libre para vender, comprar ni arrendar ${ }^{9}$. Era preciso, por tanto, la existencia de una serie de medidas que, en un breve espacio de tiempo, actuaran sobre la tierra para convertirla en una mercancía, es decir, libre de derechos adquiridos de colonos o de obligaciones tradicionales de cualquier comunidad campesina, libre para su enajenación y herencia y fácil de hipotecar... La liberalización del mercado territorial resultaba una necesidad tan extendida para

- A. Sola, "Notes per a iniciar un estudi de al desvinculació". Primer Congreso de Historia Agraria, octubre 1980, copia ciclostilada.

7 Por la testamentaría del Duque de Alba sabemos que esta casa había enajenado "fincas, rentas y derechos vinculados" por un valor de más de 7 millones de reales durante 1795-1835. A. H. de Protocolos, Madrid, Protocolo núm. 24.296.

"S. Moxo, "El Duque del Infantado Don Pedro Alcántara de Toledo...", Hispania, núm. 137 (1977), p. 597.

${ }^{9}$ Este es el sentido de las protestas de 1820 respecto al Decreto de 8 de junio de 1813 según $G$. ANEs, "La agricultura española desde comienzos del siglo xIX hasta 1868", Ensayos sobre la economía española a mediados del siglo XIX, Ariel, 1970 , p. 241. Para el tema de los cambios en el régimen de arrendamientos, R. RoBLEDO, "La evolución de la renta de la tierra en Castilla, desde comienzos del siglo xIX hasta 1885", Investigaciones Económicas, núm. 11 (1980). 
la clase social en ascenso que medidas similares hubo que arbitrar en cualquier lugar, desde Escocia hasta la India ${ }^{10}$. En España, los Decretos de Isabel II de 1836-37 se encargaban de señalar, con cierta reiteración, lo que era preciso hacer: había que cortar «los abusos de tiempos pasados al libre y completo goce del derecho de propiedad».

De las diferentes medidas burguesas, el fenómeno desamortizador que propicia la salida al mercado de un gran volumen de tierras resulta el más conocido, y puede constituir un primer punto de partida para comparaciones posteriores. Sin embargo, pese a la abundancia de estudios, se ha marginado generalmente este apartado del precio de la hectárea de tierra, que nosotros hemos tenido que deducir, a veces, de forma laboriosa. Hemos dado como buenas las cifras de tasación y no las de remate, ya que éste, al incluir el pago en títulos de la deuda por su valor nominal, nos daría una cifra desproporcionada ". Los distintos datos a partir de monografías sobre la desamortización, fuentes inéditas y los que proporciona F. Caballero se acercan a 40 , a través de los cuales se deduce una cifra media de 164 pesetas/hectárea. Después de reunida esta información, la aparición del libro de $G$. Rueda ha venido a confirmar la validez de dicha cifra, pues la media provincial vallisoletana (con más de 50.000 hectáreas en la muestra) oscila entre 167.174 pesetas (hectárea de labor, secano) y con muy poca dispersión de los valores comarcales respecto al promedio provincial (ver apéndice, pp. 271-75). En resumen, el precio medio de la hectárea de tierra de secano debió estar próximo a las 160-170 pesetas, indice en torno al cual debieron oscilar las ventas de tierras desamortizadas hasta 1845 , más o menos.

Tres o cuatro décadas después, tenemos la oportunidad de contrastar este precio con el proporcionado por los registradores de la Propiedad. Primero, para los años 1871-1875 se nos ofrece un valor medio por hectárea (sin especificar), para España, de 362 pesetas, un poco más elevado que el que resulta para la región castellano-leonesa. Diez años después, la siguiente información de los registradores apunta hacia incrementos similares. El valor

10 E. J. HobsbaWM, “Capitalisme et agriculture: Les réformateurs écossais au XVIII siècle", Annales E.S.C., mayo-junio 1978, p. 586; J. Pouchepadass, "Terre, pouvoir et marché: La naissance du marché foncier dans la plaine du gange (XIXe-XXc siècles)", Annales E.S.C., núm. 3 (1979), p. 499.

"Esto es lo que hace decir a M. ARTols (Antiguo Régimen y revolución liberal, p. 303) que, dado que los precios de adjudicación duplicaron los de tasación, "tendríamos que suponer que existía una demanda y una masa de medios de pago tan fantástica que ni siquiera la oferta masiva de tierras pudo retraerla". Por otra parte, existe el acuerdo entre diversos especialistas de que los precios de tasación se hicieron con cierta rigurosidad, aunque alguna circular (15 de febrero de 1861) ponga en duda esta opinión cuando manda a los peritos tasadores que no prescinden de medir pues "son infinitos los expedientes incoados sobre falta $o$ exceso de cabida de las fincas, lo cual prueba que se limitan a apreciar ésta por cálculo". ABells, Manual de desamortización civil y eclesiástica, Madrid, 1895. 
medio de una hectárea de secano no está deducido ahora solamente de los documentos del Registro, sino de una información externa (peritos, capitalización de la renta), y, pese a las dificultades de todas estas estimaciones, es la primera vez que tenemos una masa de datos importante - todos los partidos judiciales están representados-, lo que hace menos endeble cualquier generalización del valor medio. Este se situaría en 400 pesetas (año 1886). Que no es una cifra descaminada se comprueba si acudimos a las contestaciones de la encuesta de la Crisis Agricola o de la Comisión de Reformas Sociales. He recogido un total de 29 observaciones de la región castellano-leonesa, que daría un precio medio de 354 pesetas, sólo un 12 por 100 más bajo que la anterior, quizá por estar afectada la información por el ambiente de la crisis agropecuaria.

El conjunto y tendencia de estas cifras creo que puede extenderse a otras regiones de España, por lo menos a la meseta sur. En la provincia de Madrid, la hectárea de tierra durante $1836-42$ costaba 200 pesetas, según tasación de las tierras eclesiásticas, $\mathrm{y}$, considerando la evolución de 1836-1864, se ha calculado un incremento del 264 por 100 en los precios unitarios ${ }^{12}$. Un sistemático estudio para la provincia de Ciudad Real, y en un momento intermedio (1854-56) del período que estamos historiando, nos da el precio de 305 pesetas/hectárea de cereales, que confirma el alza escalonada de $1830-70^{13}$.

\section{A.2. Los años de la crisis y su pronta recuperación}

A través de la investigación sobre la evolución de la renta, sabemos que su inflexión en la depresión de fines de siglo no fue ni pronunciada ni prolongada, pues después de 1895 se fue generalizando la tendencia al alza de los arriendos. En consecuencia, tampoco debió resentirse demasiado la cotización de la propiedad, por más que se dejaran oír opiniones catastrofistas sobre el estado de la sociedad rural.

De momento, sin que abunden en exceso, hay informaciones de contemporáneos, como las Memorias de los registradores, que hablaron de una tendencia a la baja en los valores de la propiedad en varios distritos y de estabilidad en otros, pero no disponemos de cifras concretas que fundamenten una devaluación en la cotización de la hectárea. Incluso pueden actuar en esa etapa factores externos, como el ferrocarril, para incrementar la valorización de la tierra ${ }^{14}$. Tan sólo el estudio de Sánchez Zurro sobre la «última

12 J. Gómez MendozA, Agricultura y expansión urbana, Madrid, Alianza, 1977, página 186.

13 J. Hidalgo Tablada, ob. cit., p. 174.

"Así Medinaceli tiene el precio más alto de la provincia y la Audiencia de Burgos apunta que la atraviesa el FC. Madrid-Zaragoza, "que le permite dar pronta y ventajosa salida a sus frutos agrícolas que consumen Aragón y Cataluña". 
desamortización» permite apuntar un descenso en el precio de la tierra: de 14 montes de los que se conoce su tasación, su precio osciló entre 100-250 pesetas/hectárea, cuando en esta zona la encuesta de la Crisis Agrícola, en 1887, había situado las tierras de segunda calidad entre 200-300 pesetas. Además de esto, un elevado número de fincas se remataron a precios más bajos que los de tasación (un 60 por 100 no superó las 140 pesetas). Ciertamente, la superficie de los lotes era importante como para desanimar a pequeños campesinos, no organizados, y tampoco se trataba de tierras de primera calidad, sino de montes; pero creo que hay elementos que avalan un cierto quebranto en la cotización de la tierra a fines del XIX en aquella zona, en claro contraste con el período desamortizador de Mendizábal o de Madoz ${ }^{15}$. Ante el último saldo de la desamortización, cabe pensar que el cambio de coyuntura ha influido en un fuerte retraimiento de la demanda, por la pérdida del poder adquisitivo del labrador ante el descenso de los precios del cereal y por la más problemática colocación de los granos en los mercados periféricos, hasta entonces destino asegurado de la producción agraria.

Pero la recuperación fue temprana. A poco de empezar el siglo, las tasaciones superan las 300 pesetas, y pronto se doblaron éstas, a partir de 1906, en la zona de Valladolid antes citada. Por estas fechas contamos también con otras estimaciones que avalan una recuperación a gran escala. Merece destacarse la observación de A. Barthe, que refiere para tierras extremeñas - suponemos que de primera calidad - un precio de 1.000 pesetas/hectárea, que en pocos años ha alcanzado la duplicación o triplicación ${ }^{16}$. La posible exageración en el ritmo de aumento se diluye al conocer otras informaciones; por ejemplo, la de Maura en 1910, que ante un redactor de un periódico americano se vanagloriaba de que el valor en venta de las tierras españolas se había triplicado en el lapso de pocos años ${ }^{17}$.

Aunque estas observaciones sobre la recuperación de la crisis son valiosas, sería mejor contar con una serie de datos como los obtenidos antes, en los años ochenta, para la región castellana, objetivo que podemos cubrir en parte, pues en 1906 se publicaba lo que parecía iba a ser la continuación de las

13 D. SÁNChez ZuRRo, "La última desamortización en la provincia de Valladolid", Estudios Geográficos, núm. 120 (1970), pp. 395-440. Apreciación similar se halla en otro estudio que nombra las dificultades para hallar compradores en las subastas de unas tierras desvalorizadas: F. M." Castrilleso, "Consecuencias e influjo del proceso desamortizador (1822-1900) en una zona de Valladolid...", Cuadernos de Investigación Histórica, núm. 4 (1980), p. 219.

${ }^{16}$ Las grandes propiedades rústicas, Madrid, 1912, p. 72.

17 Lo cuenta R. de MAEzTu en "La carestía y las rentas", artículo publicado en el Heraldo de Madrid en agosto de 1910 y reproducido en La Reforma Social, año II, 1935, p. 9. Maeztu indicaba por su cuenta datos de arrendamientos extremeños que confirman esta triplicación. Puede verse también F. Sánchez Marroyo, Sindicalismo agrario y movimiento obrero (Cáceres, 1906-1920), Cáceres, 1979, páginas $\mathbf{4 1 - 4 3 .}$ 
Memorias de los registradores, referidas ahora al periodo 1887-1902. A primera vista no observamos ningún hundimiento respecto al valor de quince años atrás, y no se halla tampoco en el comentario de los registradores ninguna observación catastrófica sobre el estado de la propiedad, cuando se trata precisamente de una información que recoge bien el ámbito cronológico de la crisis. En conjunto, si agrupamos los datos de los 13 distritos castellanos, se observa un mantenimiento o ligera alza, cuando menos - nunca un descenso global-, en el precio de la hectárea de secano ${ }^{18}$.

Finalmente, contamos con un estudio de J. Cascón que permite cubrir en fechas parecidas información sobre un área diferente, la situada al centro-oeste de la región. El precio medio de una hectárea de segunda calidad se sitúa en 550-750 pesetas para los años 1908-1909. Estos y otros datos que figuran en el apéndice permiten afirmar que, al inicio del segundo decenio del siglo XX, las tierras de segunda calidad estaban por encima de las 500 pesetas, por lo menos un 20-30 por 100 más caras que al inicio de la crisis. Deflactado por el índice de precios al por mayor, el precio de la hectárea seguía siendo antes de 1913 superior en pesetas constantes al de 1880. No hay duda de que la opción proteccionista, como proyecto de reconducción del capitalismo español - tal cual lo ha explicado el Grupo de Estudios Rural en este coloquio-, había servido (sin negar las transformaciones habidas en el sector agrario) para apuntalar el antiguo predominio de la propiedad territorial.

De la coyuntura depresiva no quedaba, pues, mucho rastro y no se hundió el precio de la tierra, que siguió, por el contrario, un ascenso que debería calificarse de «irresistible». Expresado en pesetas corrientes: en 1931, la Asociación de Propietarios evaluaba la hectárea en 1.250 pesetas; hacia 1955, el perito del Instituto Nacional de Colonización tasaba diversas tierras expropiables en Salamanca entre 15.000-18.000 pesetas/hectárea; en 1975, la hectárea de labor se cotiza alrededor de $125.000-150.000$ pesetas, pero la inflación de estos años puede haber doblado este precio...

\section{B. Consideraciones sobre la evolución del precio de la tierra}

Hasta aquí hemos efectuado un análisis global del precio de la tierra, tratando de observar principalmente su tendencia y, por tanto, dejando de lado las fluctuaciones a corto plazo o - lo que sería más interesante- las

\footnotetext{
${ }^{18}$ Sólo tres partidos judiciales tienen una cifra inferior (promedio) a las 300 pesetas, mientras que siete están en el intervalo 300-600 pesetas y tres en el de más de 600 pesetas.
} 


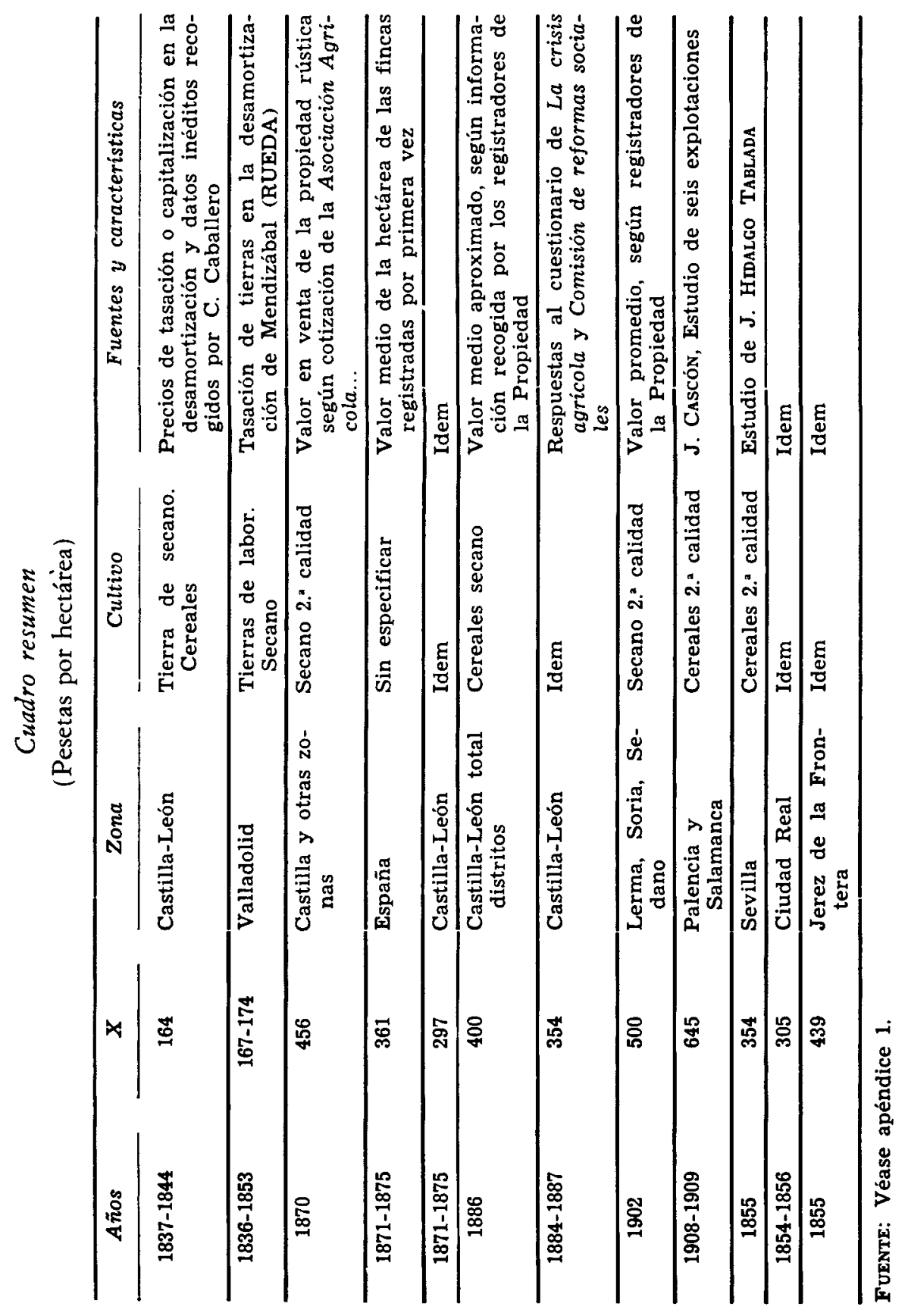


variaciones de los precios relativos de la tierra con diferentes usos agrícolas (viñedo, olivar, pastos...), según se fue modificando la coyuntura a lo largo del xix por las variaciones de la demanda interior o exterior u otras causas. Sí nos interesa reflexionar sobre tres cuestiones. ¿Cómo explicar el alza de la propiedad territorial? ¿Hasta qué punto la tierra resultaba accesible o no, bien en renta o en venta? Por último, ¿la evolución del precio de la tierra en España se asemeja a lo ocurrido en otros países europeos?

\section{B.1. El ascenso de la propiedad territorial en el siglo XIX}

A través de la exposición anterior vemos que, en las cuatro décadas centrales del XIX, el precio de la tierra se multiplicó por 2,4 ó 2,1, según que tomemos como punto de referencia la información de los registradores o de las encuestas. Ante el grado de dispersión que encierran estas informaciones, no es aconsejable darle excesiva contundencia a la media aritmética, pero la tendencia hacia una duplicación no se ve disminuida por este hecho. Como se observa a través de la distribución de frecuencias acumuladas, en los años cuarenta las tres cuartas partes de las observaciones no llegaban a las 200 pesetas, tope que la investigación sobre la provincia de Valladolid efectuada por $\mathrm{G}$. Rueda ha servido para confirmar; sin embargo, en 1886, más de las cuatro quintas partes de los datos habían superado las 200 pesetas, centrándose un 50 por 100 de la información entre las $300-750$ pesetas. De todos modos, para tener un mayor fundamento en la comparación, hemos establecido la media tipificada de las observaciones de 1840-1886. En el primer caso, un 72 por 100 se encuentra por debajo (o muy ligeramente por encima) de la media, y en el segundo, el porcentaje es del 64,2 por 100. Estamos, pues, ante una distribución bastante homogénea, que da más verosimilitud a la comparación anterior.

Por otra parte, no hace falta repetir aquí argumentos desarrollados en otro lugar ${ }^{19} \mathrm{o}$ cansar al lector con más testimonios procedentes de otras fuentes ${ }^{20}$, aunque la observación de Fermín Caballero para 1862-63 cobra tal importancia que merece su cita:

«Según los cálculos más prudentes, y tomando los datos en su conjunto, puede fijarse el precio medio de la hectárea en España actualmente en 1.300 reales y el de la renta en 52 reales, o sea, el cuatro por ciento."

${ }^{19}$ R. Robledo, "La evolución de la renta...", art. cit., pp. 85-91.

${ }^{20} \mathrm{Cfr}$. A. M. Bernal, La lucha por la tierra en la crisis del Antiguo Régimen, pp. 230-237. También examinando precios a través de inventarios se confirma este ascenso. 
Tenemos así un precio medio de 325 pesetas/hectárea que confirma la subida, aunque, según esta cifra, el ascenso sería más pronunciado de 1840 a 1860 que después ${ }^{21}$.

¿Qué sentido tienen todas estas estimaciones? $\mathrm{Y}$, en concreto, ¿a qué se puede imputar el alza sostenida del precio de la tierra?

Una primera explicación, relativamente cómoda (por su amplia utilización), se centraría en la inelasticidad del factor producción tierra ante una demanda creciente. Ocurre, sin embargo, que en las décadas que van de 1836 a 1876 se produjo en España, por primera vez, una oferta masiva de tierras, con una intensidad desconocida hasta entonces $y$, posiblemente, no igualada con posterioridad. Varios millones de hectáreas salieron al mercado, afectando a un importante porcentaje del territorio peninsular, el suficiente como para absorber (en teoría) buena parte del incremento de la población agraria ${ }^{22}$. Sin embargo, la tierra subió escalonadamente de precio, como para asombrar a un buen conocedor del campo español - F. Caballero-, para quien esta situación constituía «un fenómeno singular (...) cuando tantos millares de fincas nacionales han salido al mercado" ${ }^{23}$. Tenemos que buscar otros indicadores que nos acerquen a una explicación más satisfactoria, y uno de ellos puede ser el de la coyuntura del siglo xIx, marcada por los avances de la revolución industrial.

Para D. Landes, «el siglo xIX se vio caracterizado por una deflación prolongada que se extiende a lo largo del período 1817-1896, con tan sólo una corta interrupción de aproximadamente seis o siete años» ${ }^{24}$. Salvo esta interrupción, que él sitúa en 1850-57, la imagen depresiva del xix sería idéntica a la Baja Edad Media o a la crisis del xviI, con la salvedad de no estar acompañado por la catástrofe o la despoblación. Y la explicación hay que buscarla en las mejoras de la productividad, que hicieron descender los costos reales. Aunque, más adelante, el autor de The Unbound Prometbeus no podrá por menos de referirse a la interrupción que supuso la Gran Depresión, lo que ahora importaba era introducir ese panorama del $\mathrm{xIX}$, provocado funda-

2. Fomento de la población rural, Madrid, Imprenta Nac., 1864, 3." ed., p. 102. El Boletín de la Asociación Agricola por la Iniciativa Privada, núm. 21 (1870), avala los promedios que estamos dando.

${ }^{22}$ Hace algún tiempo que F. Simón Sigura avanzó, de forma provisional, la estimación de 10 millones de $\mathrm{Ha}$. como la superficie vendida de 1836-1900, lo que representaría un 20 por 100 de la superficie total, La desamortización española del siglo $X I X$, Madrid, I.E.F., 1973, p. 282. A esto habría que añadir la, por ahora desconocida, oferta de tierras procedente de mayorazgos...

${ }^{23}$ Fomento de la población rural, p. 102. J. Gómez Mendoza, en el libro antes citado, nos dice: "La ampliación de la oferta a lo largo del proceso no sólo no conđujo a una depreciación del suelo rústico, sino que, por el contrario, fue compatible con su revalorización", p. 189.

${ }^{24}$ Progreso tecnológico y revolución industrial, Madrid, Tecnos, p. 254. 
mentalmente por las innovaciones de la revolución industrial, incluida la revolución del transporte.

Para España, contamos con algunas magnitudes que dan cuenta del fenómeno:

\begin{tabular}{|c|c|c|c|}
\hline Sector & Precio de la indiana (rs-cts/cana) & & \\
\hline \multirow[t]{3}{*}{ Algodonero } & $\begin{array}{l}1831-1835=10,52 \\
1876-1880=3,10\end{array}$ & Descenso: & 70,6 por 100 \\
\hline & Precio hierro colado (ptas/Qm.) & & \\
\hline & Vizcaya: & & \\
\hline \multirow[t]{3}{*}{ Siderurgia } & $\begin{array}{l}1865-1867=13,3 \\
1882-1883=5,6\end{array}$ & Descenso: & 58 por 100 \\
\hline & $\begin{array}{c}\text { Guipúzcoa: } \\
1865-1867=15,0 \\
1882-1883=7,5\end{array}$ & Descenso: & 50 por 100 \\
\hline & Precio $T m / K m$. Cía. Norte (ptas.) & & \\
\hline Transporte FC. & $\begin{array}{l}1868-1869=0,097 \\
1898-1899=0,073\end{array}$ & Descenso: & 24 por 100 \\
\hline
\end{tabular}

Fuentes: Elaboración a partir de J. NADAL, El fracaso de la Revolución Industrial en España, pp. 205 y 175, y P. TEDDE, "Las compañías ferroviarias", Los ferrocarriles en España, II, Madrid, 1978, p. 99.

A diferencia de otras etapas, pues, el ascenso del precio de la tierra está teniendo lugar en pleno descenso de costos por el desarrollo de la revolución industrial. No es pura coincidencia; estamos ante una tendencia que confirma la apreciación de K. Vergopoulos: cuanto más desarrolla la industria su fuerza productiva, más se deprecia el capital y más se revaloriza la tierra ${ }^{25}$.

Ahora bien, el incremento de la renta de la tierra en el XIX no puede atribuirse únicamente a la improductividad relativa de la agricultura respecto a la producción industrial. Hay que tener en cuenta la progresiva integración del mercado interior a medida que se articulaba una red de ferrocarril o se desarrollaba la división del trabajo gracias a la industrialización catalana. De hecho, los puertos de Cataluña eran «los mejores y más seguros con que cuentan las provincias productoras de granos, sin cuyo auxilio y el de la Isla de Cuba habría quedado ya estacionaria nuestra agricultura» ${ }^{26}$. La exis-

${ }^{25}$ La cuestión campesina y el capitalismo, Barcelona, Fontanella, 1980, p. 111.

${ }^{26}$ Según el Dictamen contenido en "La información arancelaria sobre el comercio de cereales y de lana de 1847", Agricultura y Sociedad, núm. 10 (1979), p. 358. Estudio preliminar de R. Garrabou. 
tencia de estos mercados, a los que habría que sumar la oportunidad brindada por el comercio exterior europeo en algún período ${ }^{27}$, influía notablemente en elevar el precio de la tierra dedicada a cereales.

Claro está que el incipiente dominio de la producción agraria por una economía de mercado, que ayudaba a incrementar la valorización de la propiedad territorial, no hubiera sido posible si previamente la tierra no hubiese pasado a ser una mercancía en los términos expresados al principio de este estudio: fácil de enajenar, segura de hipotecar y sin obstáculos consuetudinarios para su alquiler o cercamiento.

\section{B.2. Sobre la situación del mercado territorial en renta y en venta}

El encarecimiento del precio de la tierra, a medida que iba avanzando el siglo xIx, debió situar este medio de producción cada vez más lejos del mundo de pequeños campesinos-arrendatarios, excluidos en gran parte (cuando no afectados negativamente) de las oportunidades contenidas en las medidas liberales.

Pero ¿no se modificó esta situación precisamente por la puesta en práctica de esas medidas, es decir, por la aparición en el mercado de una gran cantidad de tierras antes alejadas de él?

Si repasamos la perspectiva de fines del xvini veremos a Jovellanos cómo se quejaba de «la falta de circulación de la tierra», de modo que el "rédito de la propiedad» estaba siempre «con una terrible desproporción con su capital», ya que escasamente producirían las tierras a los propietarios el 1 por 100 de su valor en venta ${ }^{28}$. Esta situación tuvo que regularizarse al llegar las desamortizaciones, tendiendo a adecuarse los valores en renta y en venta. Frente al 1 por 100 que escandalizaba a Jovellanos, los peritos a la hora de la subasta capitalizaron la renta de las fincas rústicas al 3 por 100 en la desamortización de Mendizábal, subiendo al 4 por 100 cuando llegó la etapa de Madoz. Este aumento del 1 por 100 en la capitalización hubiera supuesto un descenso de un tercio en el precio de la tierra que salía a subasta, siempre que la renta - base de la capitalización - hubiera sido la misma entre ambas etapas; pero, como sabemos, no ocurrió así, sino que la renta tendió

27 L. Prados de LA Escosura, Comercio exterior y crecimiento económico en España, 1826-1913, Banco de España, 1982, p. 39. Después del vino, están el trigo y la harina en la etapa 1826-1849. Cfr. también J. Nadal Farreras, Comercio exterior $y$ subdesarrollo..., Madrid, 1978, pp. 243-245.

${ }^{28}$ Citado por G. ANes, "Comercio de productos y distribución de rentas", La economía agraria en la historia de España, Madrid, Alianza-J. March, 1979, p. 290. Véanse también en este mismo volumen referencias al encarecimiento de la tierra en el País Vasco ( $y$ a la necesidad consiguiente de la liberalización del mercado territorial para la clase burguesa) en E. Fernández de Pinedo y L. M." Bilbao, "Factores de evolución de la propiedad en el País Vasco", pp. 154-155. 
también a crecer, llegando probablemente a una duplicación entre 1840-80, con lo que se contrarrestaba el hipotético descenso de la tierra por efecto del aumento del tipo de capitalización.

No hay duda, sin embargo, que a mediados del xix se había alterado sensiblemente el panorama de fines del xviII, y el hecho de la gran oferta de tierras como el de los mecanismos arbitrados para su adquisición intervinieron para que, al menos los grupos sociales con más fuerza económica, compraran a precios reales más bajos que los estipulados por la tasación o capitalización de la renta ${ }^{29}$. Buen resultado - para los beneficiarios directos de las medidas liberales - si se compara con la amortización y menor circulación de la tierra en el setecientos y, por tanto, con las dificultades para que su adquisición fuera rentable en aquella época.

De todos modos, después de pasada la oportunidad desamortizadora, en la que pudo existir una participación de pequeños colonos-propietarios ${ }^{30}$, y al tiempo que no se producian - salvo excepciones periféricas - cambios sustanciales en las expectativas de empleo e inversión, el mercado de tierras tendía a estrecharse frente a una demanda en aumento a cargo de campesinos que necesitaban acudir imperiosamente a ese medio de producción si querían salvarse de la inseguridad que suponía el jornal agrícola o incluso el arriendo. El resultado no podía ser otro que el encarecimiento progresivo de la propiedad $y$, una vez superado el paréntesis de la crisis de 1886-95, se iba a

${ }^{29}$ No es posible detenerse aquí en el tema desamortizador, pero digamos, al menos, que ese trato de favor se apoyaba en la actuación de las Juntas Municipales y Junta Superior (como ha analizado F. HERAN, Tierra y parentesco en el campo sevillano..., Madrid, 1980 , pp. 93 y ss.) o en la forma de pago al aceptar títulos por su valor nominal, máxime si éstos eran indemnización de antiguas rentas o derechos feudales. Cfr. R. Robredo, "Desamortización y Hacienda Pública en algunos inventarios de grandes terratenientes del siglo xix", Santander, 1982 (Jornadas de Desamortización y Hacienda Pública). El resultado global para una provincia como Valladolid fue que de los 60.031 .544 reales a que ascendió la tasación, el Estado sólo ingresó (de 1836 a 1853) 44.776 .148 reales, es decir, que la cotización se situó un 25 por 100 por debajo de la tasación, una vez contabilizada la depreciación de los títulos. Así se deduce del estudio de G. Rueda, La desamortización de Mendizábal..., pp. 334-335. No se me atribuya, sin embargo, lo de la desamortización como un gran "fiasco", lleno de "gangas". La forma de pago cambió con Madoz y también en la etapa anterior los menos pudientes que compraron fincas tuvieron que superar las cifras reales de tasación.

${ }^{30}$ Aunque los compradores rurales se van a quedar con algo más del 50 por 100 de la tierra desamortizada en Valladolid, la parte desembolsada por lo que G. Rueda llama "clases bajas" sólo ascendió al 10 por 100 del total, ob. cit., p. 151. Para Logroño, según revela su Junta de Agricultura en 1852, la desamortización contribuyó a que muchos colonos se convirtieran en propietarios aprovechando la subdivisión de la propiedad en manos del clero secular y regular. Cfr. contestaciones a la Circular de 1849 recogidas en J. DEL MORAL, La agricultura española a mediados del siglo XIX, Madrid, Ministerio de Agricultura, 1979, p. 174. 
generalizar la disparidad entre el precio de la tierra y el de su renta. Ya antes conocíamos informes donde se acusaba al labrador de invertirlo todo en compra de tierras, «aunque éstas no le produzcan el uno o el dos del capital empleado por lo alzado de su compra» ${ }^{31}$, y a fines de siglo serán más frecuentes - con fines proteccionistas- quejas similares por la escasa rentabilidad de la propiedad agraria. No se olvide, sin embargo, que muchos de estos lamentos encierran una falacia, mantenida, entre otros, por Thiers, con unos fines ideológicos muy claros ${ }^{32}$; en realidad, como argumentaba Marx, lo que estaba demostrando Thiers en La propieté era precisamente el alto nivel del precio de compra de la tierra ${ }^{33}$.

Hay que pensar que diversas consideraciones económicas y extraeconómicas se juntaron en el caso castellano, el más conocido para mí, para que el precio de la tierra se disparase, a fines del xix y principios del $\mathrm{xx}$, en proporción superior al incremento de la renta. A la falta de alternativas económicas señaladas antes se sumaron móviles extraeconómicos, en el seno de una sociedad donde el acceso a la tierra seguía siendo señal de prestigio y de dominación sociopolítica, tal como se configuraba el sistema de elecciones en los distritos rurales. Además, a medida que crecía la conflictividad andaluza, las provincias al norte del Tajo ofrecían un elemento adicional de tranquilidad a considerar. Esto lo sabemos para Salamanca ${ }^{34}$ y no hay que descartarlo para provincias afines.

Demasiados factores ${ }^{35}$ (al margen de la inversión con fines especulativos o de las repercusiones concretas de la política arancelaria) como para no distorsionar la cotización del suelo agrario en relación con su rentabilidad económica estricta. Así, en 1914, Unamuno explicaba que había intervenido

\footnotetext{
${ }^{31}$ Asociación Agrícola..., 1869, cit. por G. RUEDA, ob. cit., p. 353.

32 "Una tierra que en 1789 valía 200.000 francos vale ahora 500.000 , algunas veces 600.00. Esa misma tierra que antes producía acaso al propietario 7.000 u 8.000 francos le produce ahora 12.000 ó 15.000 , según las mejoras hechas en el terreno. Por tanto, antes producía 3,5 y 4 por 100 y ahora 2,5 cuando más". A partir de aquí, deducía que los capitales eran más accesibles al trabajo, que los jornales eran más caros y que, en definitiva, la Providencia (sic) se encargaba de mejorar las condiciones de los laboriosos. A. Thrers, De la propiedad, Ed. Pérez, Est. Tip. de Mellado, Madrid, 1848, pp. 97-99. Esta obra fue recomendada a todos los ayuntamientos de España por Real Orden 10 octubre 1848.

${ }^{33}$ C. MarX, El Capital, México, F.C.E., tomo III, pp. 581-582.

${ }^{34}$ B. Gabriel y Galán, La propiedad territorial en la provincia de Salamanca, 1906.

${ }^{35}$ Varias de las características señaladas para el incremento del precio en el suelo urbano son aplicables también al mercado rústico: imperfección de la competencia, oferta inflexible, demanda rígida, mercado de especulación, demanda derivada... Cfr. J. J. Granelle, Espace urbain et prix du sol, cit. por Avella, El precio del suelo en Aragón, Zaragoza, 1975, p. 11.
} 
«como patrón de una fundación en la venta de una tierra que rentaba 3.000 pesetas y se vendió en ii氵182.500!!!, lo que hace poco más que el 1,6 por cien» ${ }^{36}$, y J. Cascón, en 1912, exponía otros casos de «guerra encarnizada por la tierra», con tipos asombrosos de cotización que no superaban el 2 por 100.

Por lo tanto, en torno a la I Guerra Mundial observamos cómo el precio de la tierra no se corresponde con la capitalización normal de la renta, por alta que fuera ésta; tal desfase obligaría a algún aristócrata vendedor de tierras a ajustar la renta de sus colonos a un tipo de interés más bajo del usual si quería cobrar lo que él creía que valía «su» finca ${ }^{37}$. La paradoja era que estos y otros colonos, cuyas tierras a comprar se les ajustaban al 2-3 por 100, debían adquirir dinero que les costaba, cuando menos, el doble de ese interés, siempre que no acudiesen al préstamo usurario...

\section{B.3. El caso español en el contexto europeo}

El indiscutible aumento del precio de la tierra no tiene parangón con la evolución de otras variables que afectan al sector agrario, como el de la producción por hectárea ${ }^{38}$, el precio del cereal o el de la fuerza de trabajo. A grandes rasgos, el precio del trigo no superó - salvo 1857 y 1868 - aumentos del 60 por 100 , y esto en la época «dorada» de la agricultura hispana ${ }^{39}$. $\mathrm{Y}$ en cuanto al salario agrícola, siempre más complejo de medir, contamos con dos marcos de referencia que, en un lapso de medio siglo, permiten afirmar la estabilidad del salario en términos monetarios: de 1850 a 1904 estuvo oscilando entre $4-6$ reales $^{40}$. Claro que hay distintas faenas y condiciones de mantenimiento, pero una vez cuantificados permiten establecer resultados

${ }^{36}$ "Campaña agraria" (marzo de 1914), en Obras Completas, Madrid, Esceliver, VII, p. 560 .

${ }^{37}$ Así tuvo que ocurrir en el pueblo de Cerralbo. Su marqués quería 1,250.000 pesetas, cifra que sólo se conseguía rebajando la capitalización de la renta (45.000 ptas.) del 4 al 3,64 por 100. M. SÁnchez, Cerralbo, 1837-1976. Tesis de licenciatura inédita, Bellatera, p. 93. Queda fuera de nuestro marco temporal explicar los cambios a partir de la primera guerra mundial. Por una parte, el propietario forzado a vender si no ha sabido sortear los peligros de la inflación; a la inversa, desde la demanda, arrendatarios favorecidos doblemente por el precio de las subsistencias y arriendos estipulados en dinero.

${ }^{38} \mathrm{R}$. ROBLEDo, "La evolución de la renta...", pp. 91-95.

39 A ese 60 por 100 se llegaría comparando las cifras más bajas de la serie $(1849-1851=15 \mathrm{ptas} / \mathrm{Hl}$.) con las más altas de 1879-1881 (=24 ptas.), según datos de la Comisión de la Encuesta sobre la Crisis Agraria, La crisis agricola y pecuaria, tomo II.

${ }^{4}$ Nos basamos en la cuesta firmada por Bravo Murillo en 1849 y que ha sido objeto de estudio de A. García Sanz y J. del Moral, y en la Información del I.R.S. 
similares ${ }^{41}$. En términos relativos, si en 1840 eran precisos $35-40$ jornales para adquirir una hectárea de secano, cuatro décadas después hacían falta de 80 a 100, aproximadamente, y esto en unos momentos en que la seguridad en el empleo era más débil que antes.

El auge en la cotización de la tierra también tuvo lugar en Europa, pero, por lo que sabemos para Francia, los salarios crecieron más deprisa que el precio de la tierra, permitiendo al campesino ahorrar lo suficiente para adquirir más tierra por día de trabajo ${ }^{42}$. El encarecimiento de la tierra en España aparece, pues, desproporcionado respecto a otras variables y sobresale, seguramente, en la comparación europea de mediados del xix; pero donde resulta más decisivo el contraste es en la etapa de fines de siglo, con motivo de la «Gran Depresión», bisagra que cerraba la etapa de los «años dorados» - la del «buen precio del trigo y la del beneficio preservado por la revolución industrial» ${ }^{43}$ - y abría la que nos enfrentaba con una nueva división internacional del trabajo, generadora de unos desequilibrios y desigualdades que aún seguimos heredando.

Aunque la deflación que singulariza la etapa no hay por qué exclusivizarla en el sector agrario, fue en el mundo rural donde dejó sus huellas más importantes, y dio lugar a frecuentes movimientos de opinión y "Ligas agrarias» que contaron también con el apoyo de los «industriales». Ahora bien, dentro de las dificultades de una coyuntura adversa, las que afectaban a los ingresos del propietario rentista adquirieron un relieve especial, por el protagonismo político del que disponían en la mayoría de los países y por el modelo social que les acompañaba.

No vamos a hablar ahora ${ }^{44}$ de la caída de la renta, iniciada en 1878 en Inglaterra, alrededor de 1880 en Francia o en 1884 en Italia, y cómo en vísperas de la Gran Guerra -aunque la coyuntura ya no es la misma- es difícil ver superadas las cotas alcanzadas antes de 1880 . Un panorama que Labrousse calificaría como la «paupérisation du rentier» ${ }^{45}$, después de ciento cincuenta

en 1904. A fines del siglo xIx, la investigación de la Comisión de Reformas Sociales y la encuesta de El Norte de Castilla confirman estas cifras del salario masculino "a seco" (invierno).

"A. M. Bernal, La lucha por la tierra..., pp. 407-408.

"2 P. K. O'Brien, "La contribución de la agricultura a la industrialización de Gran Bretaña y Francia", Moneda y Crédito, núm. 158 (1981), p. 56.

${ }^{4}$ E. Labrousse, Fluctuaciones económicas e historia social, Madrid, Tecnos, 1973, página 348.

"Próximamente se publicará en Estudios de Historia Económica, núm. 11, una parte de la tesis, ampliada con otros materiales, que darán razón de afírmaciones muy resumidas de este último apartado.

${ }^{45}$ Prefacio de E. Labrousse al libro citado de M. Lévy Leboyer, p. XI. 
años de ascenso (con la excepción de la coyuntura postnapoleónica) del tradicional ingreso de la clase propietaria.

El precio de la tierra, del que nos venimos ocupando, permite observar el contraste internacional:

\section{Precio de la tierra}

(Indice $100=1879-1886$ )

\begin{tabular}{|c|c|c|c|c|c|c|c|c|}
\hline \multicolumn{3}{|c|}{ FRANCLA } & \multicolumn{3}{|c|}{ ESPAÑA (Castilla) } & \multicolumn{3}{|c|}{ GRECIA } \\
\hline Años & $\begin{array}{c}\text { Francos/ } \\
\text { Ha. }\end{array}$ & Indice & Años & $\begin{array}{l}\text { Ptas/ } \\
\text { Ha. }\end{array}$ & Indice & $A$ ños & $\begin{array}{c}\text { Drac- } \\
\text { mas }\end{array}$ & Indice \\
\hline 1831 & 800 & (44) & 1840 & 170 & (45) & - & - & - \\
\hline 1879 & 1.830 & $(100)$ & 1886 & 377 & $(100)$ & 1880 & 11 & $(100)$ \\
\hline 1912 & 1.244 & (68) & 1910 & 600 & (159) & 1896 & 22 & (200). \\
\hline & & & & & & 1917 & 66 & $(600)$ \\
\hline
\end{tabular}

Fuentes: Para Francia, Histoire de la France rurale, tomo III, pp. 139 y 403 . Los datos proceden de encuestas fiscales; y en Grecia, K. Vergopoulos, Le capitalisme difforme et la nouvelle question agraire de la Grèce moderne, París, Masperó, 1977, p. 115. Las cifras castellanas son promedio de las estimaciones que figuran en páginas anteriores. El dato de 1910 es muy aproximado y calculado más bien a la baja.

Si se me permite generalizar a partir de los ejemplos extraídos de la región castellana sobre el caso español (lo que no deja de ser un cierto abuso), el lugar que le correspondería estaría mucho más cerca de Grecia que del de Francia. Opino que hay una serie de elementos comunes - -en los que también participa Portugal- que no terminan en la evolución del precio de la tierra, sino que se centran también en las distintas relaciones establecidas entre propietarios-arrendatarios $y$, en definitiva, en las formas de penetración del capitalismo en el campo en estas penínsulas mediterráneas. Además, la coincidencia en estas y otras características (ritmo de emigración exterior, expansión colonial...) que uno encuentra también en Italia, o al menos en el Mezzogiorno, avalan el planteamiento de un modelo mediterráneo de salida de la crisis finisecular muy diferenciado del de los países noroccidentales, contraste que seguramente no nacía ahora, sino que tenía hondas raices. En concreto, la Gran Depresión había constituido, en el peor de los casos, un bacbe superado en corto espacio de tiempo, más que una ruptura que forzara 
a cambios importantes; todo ello con la consolidación de un bloque social agrario-industrial de corte muy conservador.

Por lo que al caso español se refiere, las consecuencias de este alineamiento iban a tener repercusiones de largo alcance. Al haberse limitado, por la actuación de unos grupos sociales, los efectos de la coyuntura depresiva - que se dirigia a la quiebra de las bases materiales del propietario rentista ${ }^{46}$ - se retrasó casi en medio siglo lo que luego tuvo que hacerse muy forzadamente en la II República, con un ambiente hostil interno y muy poco propicio también internacionalmente.

4 Cfr. R. Garrabou, "La crisi agrària espanyola de finals del segle xrx", Recerques, núm. 5 (1975). Por leve que hubiera sido la caída de la renta o la depreciación de la tierra, una prolongación de esta situación hubiera puesto en apuros a gran parte de la propiedad rentista fuera o no aristócrata. El estudio que he hecho sobre sus fortunas alrededor de 1870 nos revela unos patrimonios de varios millones de pesetas, pero de escasa validez. Muy pocos valores mobiliarios, apenas dinero ent metálico y la inercia de mantener un rango social hubieran colocado a estas casas en un callejón sin salída (a merced de prestamistas privados) cuando más del 80 por 100 de sus ingresos dependían de la renta territorial. 


\section{APENDICE}

\section{Fuentes para elaborar el precio de la tierra}

\section{a) Area de estudio y medidas de superficie}

La mayoría de las estimaciones están referidas a la región castellanoleonesa y ofrecen información de tierras de calidad media, de secano, casi siempe de cereales; circunstancias que en conjunto permiten extender, en cierto modo, estos datos a otras zonas de la Península. Esta extrapolación resulta cada vez menos arriesgada a medida que avanza el siglo xIX, y la integración de un mercado nacional de productos agrícolas va amortiguando las disparidades de los precios.

En cuanto a las medidas, fanega y huebra, por lo general, se han hecho equivalentes a 44,72 áreas, pero si la fanega es de marco real $=64,39$ áreas; la obrada de 400 estadales $=39,30$, y la obrada, en Valladolid, de 200 estadales $=28,29$. Para Zamora, hemos supuesto que se trataba de fanega de 300 estadales, $\mathrm{y}$ entonces $=33,55$ áreas.

\section{b) Precio de la tierra en torno a 1840. Desamortización}

Para tierras desamortizadas partimos de estudios relativos a las provincias de Salamanca y Valladolid: T. Martín, «La desamortización del Convento de San Esteban...», Ciencia Tomista, 1973, y artículos de G. Rueda publicados en Cuadernos de Historia Económica de Cataluña (1976) y Moneda y Crédito (1976). En este último ( «Los beneficiarios del proceso desamortizador...») hemos tenido que deducir la información a través de la biografía de los compradores y buscar luego, en el apéndice general, nombre del comprador y tasación.

Como fuentes inéditas, he consultado las ventas del Cabildo y Mitra de Zamora en el A. H. P. de la ciudad, reproducidas como apéndice en la ponencia presentada al II Coloquio de Historia Económica. El precio por hectárea del que hemos partido es el más alto cuando se puede elegir entre tasación y capitalización.

A estas cifras he agregado las que proporciona F. Caballero (Fomento de la población rural, p. 101), apoyándose en datos inéditos de V. Sancho del año 1838, y concretadas en tierras de pan llevar para Castilla, excluyendo el caso anómalo de Burgos (casi 1.000 pesetas/hectárea). La agrupación de todas estas informaciones nos da el resultado siguiente: 


\section{CUADRO 1 \\ Castilla-León, $1837-44$}

\begin{tabular}{|c|c|c|c|c|}
\hline Pesetas & Observac. & $\begin{array}{c}\text { Frecuencia } \\
(\%)\end{array}$ & Acumuladas & \\
\hline \multirow[t]{2}{*}{$\begin{array}{rrrrrrr}\text { De } & 0 & 0 & 100 & 100 & \ldots & \ldots \\
\text { De } & 101 & \text { a } & 200 & \ldots & \ldots & \ldots \\
\text { De } & 201 & \text { a } & 300 & \ldots & \ldots & \ldots \\
\text { De } & 301 & \text { a } & 400 & \ldots & \ldots & \ldots \\
\text { De } & 401 & \text { a } & 500 & \ldots & \ldots & \ldots\end{array}$} & $\begin{array}{r}10 \\
17 \\
7 \\
1 \\
1\end{array}$ & $\begin{array}{r}27,8 \\
47,2 \\
19,4 \\
2,8 \\
2,8\end{array}$ & $\begin{array}{r}27,8 \\
75,0 \\
94,4 \\
97,2 \\
100\end{array}$ & $\begin{array}{l}\bar{X}=164,47 \\
S=87,2 \\
V=53\end{array}$ \\
\hline & 36 & 100,0 & & \\
\hline
\end{tabular}

Una fuente valiosa, por el volumen de hectáreas que fueron tasadas (para su subasta), es la relativa a la provincia de Valladolid en la desamortización de Mendizábal.

\section{CUADRO 2}

Precio de la bectárea de tierra de labor (secano). Provincia de Valladolid

\begin{tabular}{|c|c|c|c|}
\hline Comarcas & Ha. labor & Tasación (reales) & Pesetas/Ha. \\
\hline $\begin{array}{llllllll}\text { Campo Pisuerga } & \ldots & \ldots & \ldots & \ldots & \ldots & \ldots & \ldots \\
\text { Páramos Esgueva } & \ldots & \ldots & \ldots & \ldots & \ldots & \ldots \\
\text { Campo Peñafiel } & \ldots & \ldots & \ldots & \ldots & \ldots & \ldots & \ldots \\
\text { Tierra Pinares } & \ldots & \ldots & \ldots & \ldots & \ldots & \ldots & \ldots \\
\text { Tierra Vino-Medina } & \ldots & \ldots & \ldots & \ldots & \ldots & \ldots \\
\text { Montes Torozos } & \ldots & \ldots & \ldots & \ldots & \ldots & \ldots & \ldots \\
\text { Tierra Campos } & \ldots & \ldots & \ldots & \ldots & \ldots & \ldots & \ldots\end{array}$ & $\begin{array}{r}4.786 \\
2.731 \\
784 \\
7.833 \\
12.686 \\
6.184 \\
19.226\end{array}$ & $\begin{array}{r}3.523 .213 \\
1.424 .223 \\
458.921 \\
5.771 .978 \\
6.865 .005 \\
4.952 .443 \\
14.732 .309\end{array}$ & $\begin{array}{l}184 \\
130 \\
146 \\
184 \\
135 \\
200 \\
192\end{array}$ \\
\hline $\begin{array}{lllllll}\text { Provincia } & \ldots & \ldots & \ldots & \ldots & \ldots & \ldots\end{array}$ & 54.230 & 37.728 .082 & 174 \\
\hline
\end{tabular}

Elaborado a partir de G. RUEDA, La desamortización de Mendizábal en la provincia de Valladolid (1836-1855), Valladolid, 1980, p. 453. Estas tierras se vendieron divididas en 52.756 parcelas. La media aritmética a partir de los datos comarcales es de 167 pesetas. $S=29$ y $V=17$.

c) Boletines $y$ encuestas, años 1870-1887

La Asociación agricola por la iniciativa privada, con sede en Valladolid, publicó con alguna periodicidad una revista que, además de discursos más o menos liberales, informaba del mercado de varios productos agrícolas en di- 
versos puntos de la geografía española y también del valor en venta de la propiedad rústica. El referente a 1870 (núm. 21, p. 370), que me ha sido facilitado por R. Garrabou, sitúa la hectárea de secano de primera calidad en 740 pesetas, y en 456 y 217 las de segunda y tercera calidad. Entran en la muestra varios lugares castellanos, pero también algunos de Aragón y Andalucia,

Son de interés también las contestaciones que a la información sobre La Crisis Agrícola y Pecuaria y Comisión de Reformas Sociales dieron ayuntamientos y otros organismos. Haciendo promedio de las tres calidades y, en algún caso, media ponderada (por el mayor peso de segunda y tercera calidad), tenemos el siguiente cuadro:

\section{CUADRO 3}

Castilla-León, 1884-1887. Encuestas

\begin{tabular}{|c|c|c|c|c|}
\hline Pesetas & Observac. & $\begin{array}{c}\text { Frecuencia } \\
(\%)\end{array}$ & Acumuladas & \multirow{3}{*}{$\begin{array}{l}\bar{X}=354,7 \\
S=122 \\
V=34\end{array}$} \\
\hline \multirow[t]{2}{*}{$\begin{array}{rrrrrrr}\text { De } & 0 & \text { a } & 150 & \ldots & \ldots & \ldots \\
\text { De } & 151 & \text { a } & \mathbf{3 0 0} & \ldots & \ldots & \ldots \\
\text { De } & 301 & \text { a } & \mathbf{4 5 0} & \ldots & \ldots & \ldots \\
\text { De } & \mathbf{4 5 1} & \text { a } & 600 & \ldots & \ldots & \ldots \\
\text { De } & 601 & \text { a } & 750 & \ldots & \ldots & \ldots \\
& & & & & & \end{array}$} & $\begin{array}{r}0 \\
11 \\
10 \\
7 \\
1\end{array}$ & $\begin{array}{r}0,0 \\
37,9 \\
34,5 \\
24,1 \\
3,5\end{array}$ & $\begin{array}{r}0,0 \\
37,9 \\
72,4 \\
96,5 \\
100,0\end{array}$ & \\
\hline & 29 & 100,0 & & \\
\hline
\end{tabular}

d) Informaciones de los registradores de la Propiedad, 1871-1902

Una vez en funcionamiento la Ley Hipotecaria de 1861 y, con ella, el Registro de la Propiedad, disponemos de una fuente que permite reflejar para toda España el movimiento de las inscripciones de fincas y el de las enajenaciones, entre otros conceptos.

d.1) A cargo del Ministerio de Gracia y Justicia se edita la Estadistica del Registro de la Propiedad 1871-1873, y 1874-1876, publicadas en Madrid en 1875 y 1878 , respectivamente, y que he podido consultar gracias a J. Sanz. Unas 300.000 fincas rústicas fueron registradas "por primera vez» anualmente de 1871 a 1876 . El valor medio por hectárea de estas inscripciones es de 361 pesetas como promedio peninsular, mientras que el de Castilla-León (excluyendo Soria) es de 297 pesetas/hectárea.

d.2) Dirección General de los Registros Civil y de la Propiedad y del Notariado: Memorias y estados formados por los Registradores de la Propiedad, Madrid, 1896, 4 tomos. 
Se dan datos sobre «el valor medio aproximado de una hectárea de terreno», referido a 1886, para cada uno de los partidos judiciales y para los distintos cultivos y aprovechamientos (en secano y regadío). Para tal fin, los registradores necesitaron acudir a las oficinas de administración, ayuntamientos, comisiones de evaluación y peritos agrónomos. Si prescindimos del precio de Burgos -3.000 pesetas/hectárea-, pues se trata probablemente de un error de impresión (secano y regadío costarían entonces lo mismo), contamos con el siguiente resumen:

\section{CUADRO 4}

Castilla-León, 1886

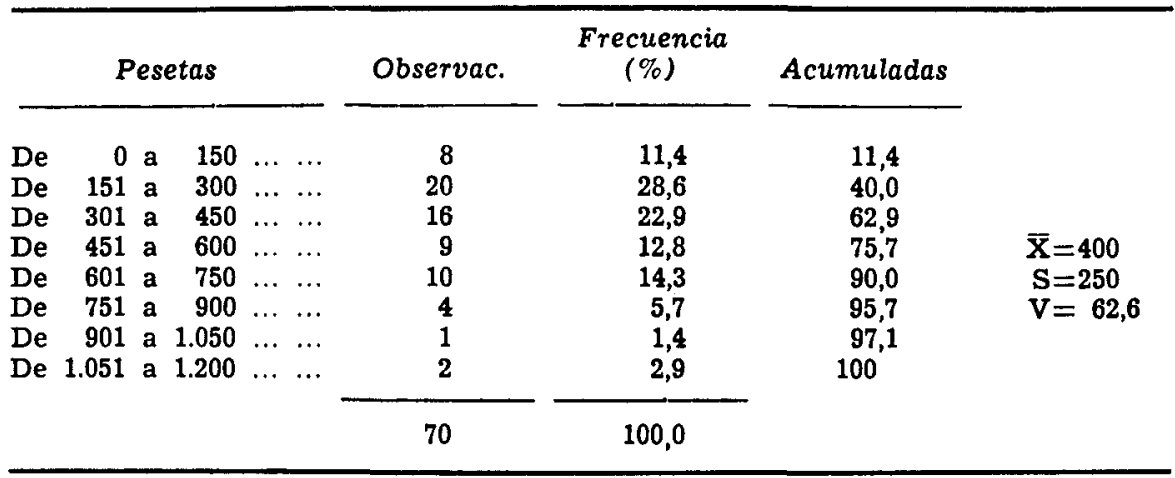

d.3) Por la misma Dirección General se publica, en 1906, Datos para el estudio de la propiedad inmueble en España. Resúmenes de las Memorias redactadas por los Registradores de la propiedad en cumplimiento del $R$. D. de 1902, Madrid, Imprenta Ibérica, 1906. No apareció más que un primer volumen, siendo la Audiencia de Burgos - que cubre, entre otras, las provincias de Burgos y Soria- la única representación castellana disponible. Realizada con diferentes criterios que la encuesta anterior - da noticia de unos ayuntamientos en la columna de máximos y de otros diferentes en la de valores mínimos-, no permite comparación adecuada con los distritos anteriores, aunque hay estimaciones a considerar cuando se especifican calidades.

\section{e) Algunos datos a principios del $X X$}

José Cascón, «Monografías de explotaciones típicas castellanas (Datos económicos)», publicado primeramente por la Asociación de Agricultores y reedi- 
tado en 1931 en el volumen Agricultura Española. Se trata del análisis de seis explotaciones de Palencia y Salamanca en los años 1908-1909. El resumen, por lo que respecta al precio de la tierra, es el siguiente:

\begin{tabular}{|c|c|}
\hline & $\begin{array}{l}\text { Hectárea de segunda calidad } \\
\text { o media de tres calidades }\end{array}$ \\
\hline Mazariegos & 648 ptas. \\
\hline Dueñas $\ldots$ & $743 \gg$ \\
\hline Revilla de C. .......... & $538-559$ \\
\hline $\begin{array}{lllllll}\text { Berrueces } & \ldots & \ldots & \ldots & \ldots & \ldots\end{array}$ & 600 \\
\hline $\begin{array}{cccccc}\text { Arconada } & \ldots & \ldots & \ldots & \ldots & \ldots\end{array}$ & 665 \\
\hline $\begin{array}{llllll}\text { Salamanca } & \ldots & \ldots & \ldots & \ldots & \ldots\end{array}$ & 766 \\
\hline
\end{tabular}

Otras estimaciones a considerar son las que da la Junta Consultiva Agronómica; por ejemplo, en Prados y Pastos, Madrid, 1908. Salamanca tiene el precio medio de 500 pesetas. Informaciones orales, a propósito de la venta de pueblos, confirman estos precios; así, San Muñoz - 2.500 hectáreas- se vendió en 1904 por 4 millones de reales (400 pesetas/hectárea).

\section{f) Un estudio sistemático, el de J. Hidalgo Tablada}

Curso de Economia rural, Madrid, 1864, 2 vols. Se dan precios del olivar, viñas, cereales, pasto y monte. La provincia de Sevilla aparece dividida en doce zonas, y se proporciona precio hasta de ocho o diez calidades diferentes. "Trabajo largo y complicado", como lo calificaba su autor, a base de registrar los precios de venta mensuales de un año y hacer luego la media de un quinquenio. La media de la provincia sevillana de $1850-55$ es de 354 pesetas/hectárea (cereal de secano), que refleja la mejor calidad de las tierras respecto a Castilla-León. Un esfuerzo similar para la provincia de Ciudad Real da el precio medio de 305 pesetas la hectárea. También se estudia el caso de Jerez de la Frontera. 